\title{
PENGARUH TINGKAT PENDIDIKAN DAN TINGKAT PENDAPATAN TERHADAP BENTUK PENGELOLAAN SAMPAH AORGANIK RUMAH TANGGA DI DESA ALASANGKER
}

\author{
Kadek Rini Jayanti, Putu Indra Christiawan, Made Sarmita \\ Jurusan Pendidikan Geografi \\ Universitas Pendidikan Ganesha \\ Singaraja, Indonesia \\ Email: jayantirini95@yahoo.co.id, putu.ic87@gmail.com, \\ madesarmita@ymail.com
}

\begin{abstract}
Abstrak
Penelitian ini dilaksanakan di Desa Alasangker, Kecamatan Buleleng, Kabupaten Buleleng yang bertujuan untuk (1) menganalisis pengaruh tingkat pendidikan terhadap bentuk pengelolaan sampah anorganik rumah tangga di Desa Alasangker dan (2) menganalisis pengaruh tingkat pendapatan terhadap bentuk pengelolaan sampah anorganik rumah tangga di Desa Alasangker. Penelitian ini menggunakan rancangan penelitian kuantitatif dengan jumlah sampel subjek yaitu $77 \mathrm{KK}$. Data diperoleh dengan teknik wawancara terstruktur dan dianalisis secara kuantitatif.

Hasil penelitian menunjukkan bahwa (1) variabel tingkat pendidikan secara parsial mempunyai pengaruh positif dan signifikan terhadap bentuk pengelolaan sampah anorganik rumah tangga di Desa Alasangker dengan signifikansi kurang dari 0,05 yaitu sebesar 0,001 dengan nilai t 0,328; (2) variabel tingkat pendapatan secara parsial mempunyai pengaruh positif dan signifikan terhadap bentuk pengelolaan sampah anorganik rumah tangga di Desa Alasangker dengan signifikansi kurang dari 0,05 yaitu sebesar 0,000 dengan nilai t 0,565 . Hasil uji regresi linier berganda diperoleh, yang paling berpengaruh adalah tingkat pendapatan.
\end{abstract}

Kata Kunci: Pendidikan, Pendapatan, Pengelolaan Sampah, Sampah Anorganik

\section{ABSTRACT}

This research was conducted in Alasangker Village, Buleleng Sub-District, Buleleng Regency which aims to (1) analyze the influence of education level on the form of household inorganic waste management in Alasangker Village and (2) to analyze the influence of income level on household inorganic waste management form in Alasangker Village. This research uses quantitative research design with the number of subject samples is $77 \mathrm{KK}$. Data were obtained by structured interview technique and analyzed quantitatively.

The result of this research shows that (1) the variable of education level partially has a positive and significant influence on the form of household 
inorganic waste management in Alasangker Village with significance less than 0,05 that is 0,001 with $t$ value 0,328 ; (2) income level variable partially have a positive and significant influence on the form of household inorganic waste management in Alasangker Village with significance less than 0,05 that is 0.000 with $t$ value 0,565. Multiple linear regression test results obtained, the most influential is the level of income.

Keywords: Education, Income, Waste of Management, Anorganic Waste

\section{PENDAHULUAN}

Sampah merupakan bahan padat buangan dari kegiatan rumah tangga, pasar, perkantoran, rumah penginapan, hotel, rumah makan, industri, puingan bahan bangunan, dan besi-besi tua bekas kendaraan bermotor (Sucipto, 2012). Klasifikasi sampah berdasrkan sifat dan asalnya terdiri atas sampah organik dan sampah anorganik (Migristine, 2014). Menurut Himawanto (2007), sampah jenis organik terdiri dari kertas dan dedaunan sedangkan dari jenis anorganik yaitu plastik dan kaca/botol. Sampah anorganik yang paling sulit diatasi adalah sampah anorganik. Menurut hasil observasi disalah satu toko penyuplai kantong plastik terbesar di Kota Singaraja, setiap bulannya bergulir 200 karung besar plastik yang masuk ke Kota Singaraja yang di pasarkan di Kecamatan Buleleng. Perguliran 200 karung item plastik ini tersedia karena pertimbangan kebutuhan dan permintaan di masyarakat yang tinggi. Satu karung yang digulirkan mengandung 200 item kantong plastik (plastik unyil), sedangkan 1 item mengandung 50 pcs kantong plastik. Maka dari itu, setiap bulannya terdapat 2 juta kantong plastik yang didistribusikan dan digunakan oleh masyarakat Kecamatan Buleleng. Itu artinya permasalahan lingkungan akan muncul di Kecamatan Buleleng. Data tersebut belum termasuk jenisjenis produk lainnya yang dirinci seperti botol kemasan mineral, kemasan kudapan ringan, kantong plastik sedang maupun besar.
Sampah anorganik yang semakin tinggi jika tidak diimbangi dengan pengelolaan sampah yang baik tentunya akan mengakibatkan kerusakan pada lingkungan (Marleni, 2012). Seperti permasalahan yang ada di Desa Alasangker, terdapat sekolah menengah pertama yaitu SMP Negeri 7 Singaraja yang sudah berdiri sekitar 10 tahun. Dengan adanya sekolah ini maka sampah anorganik akan semakin meningkat hasil dari sisa aktivitas siswa yang dibuang, jadi siswa sebagi penggerak sampah anorganik. Contohnya jika siswa diberikan pekerjaan rumah oleh guru disekolahnya maka siswa itu akan mengerjakan tugasnya di rumahnya masing-masing tentunya dalam mengerjakan tugas tersebut akan menghasilkan sampah anorganik. Sampah yang dihalsilkan dari aktivitas siswa yaitu bekas pulpen, plastik tempat pembungkus makanan, botol plastik, dan plastik pembungkus minuman. Sumber sampah juga terdapat dari masyarakat khususnya yaitu sampah rumah tangga, sampah rumah tangga merupakan jenis sampah yang banyak diproduksi dan paling banyak dibuang sembarangan tanpa dilakukan pemilihan atau pengelolaan terlebih dahulu (Fitriana dan Soedirham 2013) Jenis sampah pada tingkat rumah tangga berupa botol kaca, tas plastik, botol plastik, tas plastik, dan kaleng.

Pengelolaan sampah sebelum dan sesudah adanya sekolah ini, masih tetap sama baik itu sampah 
organik maupun sampah anorganik. Jika dulu sebagian besar sampah yang ada di Desa Alasangker adalah sampah organik dan cara pengelolaannya hanya di buang di tegalan, maka sampah tersebut akan cepat terurai dan tidak akan menimbulkan masalah yang besar. Sesudah adanya SMP Negeri 7 Singaraja dan adanya sampah rumah tangga yang dominan sampah tersebut adalah sampah anorganik, pengelolaan sampah masih sama maka tentu akan menimbulkan banyak masalah karena sampah anorganik sulit terurai.

Pengelolaan sampah sudah diatur dalam Undang-Undang RI No. 18 Tahun 2008 tentang Pengelolaan Sampah. Pengelolaan sampah di Desa Alasangker dapat dikatakan tidak tepat, karena pengurangan sampah rumah tangga dan sampah sekolah dibuang di tegalan, di sungai dan ada juga masyarakat yang membakar sampah. Pengurangan sampah yang dilakukan oleh masyarakat Desa Alasangker yaitu membuang sampah di tegalan, meskipun sudah ada papan larangan untuk tidak membuang sampah di tempat tersebut, namun masyarakat Desa Alasangker masih saja ada yang membuang sampah di tempat tersebut. Oknum masyarakat masih mengidap salah satu sindrom mengenai lingkungan yang mengatakan bahwa masyarakat saat ini melakukan pembersihan hanya di

\section{METODE}

Penelitian ini dilakukan di Desa Alasangker. Objek dalam penelitian ini adalah tingkat pendidikan, tingkat pendapatan dan bentuk pengelolaan sampah anorganik, yang menjadi subjek penelitian adalah kepala keluarga di Desa Alasangker. Populasi penelitian adalah seluruh rumah saja. Artinya, jika di rumah bersih maka tidak diperhatikan lingkungan sekitar seperti lahan kosong maupun sungai. Fenomena ini jika dibiarkan maka akan berdampak negatif bagi lingkungan. Selain berdampak negatif terhadap lingkungan tercatat lebih dari 25 jenis penyakit yang disebabkan oleh buruknya pengelolaan sampah, salah satunya diare (Sucipto, 2012).

Hasil penelitian Beni, Martinus Tulit, dkk (2014) menunjukkan jenjang/tingkat pendidikan yang ditamatkan kepala rumah tangga berpengaruh nyata terhadap pengelolaan sampah rumah tangga. Tingkat pendapatan juga berhubungan positif terhadap pengelolaan sampah rumah tangga (Suprapto, 2010).

Permasalahan penelitian ini (1) Bagaimana
pengaruh tingkat pendidikan
terhadap bentuk pengelolaan
sampah anorganik rumah tangga di Desa Alasangker, (2) Bagaimana pengaruh tingkat pendapatan terhadap bentuk pengelolaan sampah anorganik rumah tangga di Desa Alasangker.

Tujuan pada penelitian ini yaitu (1) Menganalisis pengaruh tingkat pendidikan terhadap bentuk pengelolaan sampah anorganik rumah tangga di Desa Alasangker, (2) Menganalisis pengaruh tingkat pendapatan terhadap bentuk pengelolaan sampah anorganik rumah tangga di Desa Alasangker.

masyarakat Desa Alasangker berjumlah 1,684 KK dan sampel subjek berjumlah 77 KK. Teknik pengumpulan data ada dua yaitu wawancara terstruktur dan pencatatan dokumen. Data primer yang telah dikumpulkan selanjutnya akan dianalisis menggunakan 
analisis kuantitatif dengan menggunakan pendekatan ekologi. Pengaruh tingkat pendidikan dan tingkat pendapatan terhadap bentuk

\section{HASIL DAN PEMBAHASAN}

\section{Analisis Regresi Linier Sederhana}

Analisis data merupakan tahapan kegiatan dalam mengolah data penelitian yang terkumpul untuk kemudian diinterpretasikan (Christiawan dan Citra, 2016). Analisis regresi linier sederhana, yaitu analisis yang digunakan untuk mengidentifikasi pengaruh dari variabel tingkat pendidikan terhadap bentuk pengelolaan sampah pengelolaan sampah anorganik rumah tangga di Desa Alasangker dianalisis menggunakan rumus linier berganda.

\section{Tabel 1. Mengenai Tingkat Pendidikan dengan Bentuk Pengelolaan}

anorganik rumah tangga dan pengaruh tingkat pendapatan terhadap pengelolaan sampah anorganik rumah tangga. Hasil perhitungan analisis linier berganda yang dijabarkan dengan menggunakan program SPSS versi 22. hasil analisis regresi linier berganda disajikan pada Tabel 4.31 berikut.

\begin{tabular}{|ll|r|r|}
\hline & & $\begin{array}{c}\text { Tingkat_pend } \\
\text { idikan }\end{array}$ & $\begin{array}{c}\text { Bentuk_peng } \\
\text { elolaan }\end{array}$ \\
\hline Tingkat_pendidikan & Pearson Correlation & 1 &, $555^{\text {Nx }}$ \\
& Sig. (2-tailed) & 77 &, 000 \\
& $\mathrm{~N}$ &, $555^{\mathrm{N}}$ & 77 \\
\hline Bentuk_pengelolaan & Pearson Correlation &, 000 & 1 \\
& Sig. (2-tailed) & 77 & 77 \\
& $\mathrm{~N}$ & & \\
\hline
\end{tabular}

**. Correlation is significant at the 0.01 level (2-tailed).

Sumber: Pengolahan Data Primer, 2017

Berdasarkan Tabel 4.31 korelasi antara tingkat pendidikan dengan bentuk pengelolaan sampah adalah 0,555 dengan signifikan
0,000. Hasil tersebut menunjukkan bahwa hubungan antara tingkat pendidikan dan bentuk pengelolaan sampah adalah erat atau kuat.

\section{Tabel 2. Hasil Analisis Regresi Linier Sederhana Mengenai Tingkat Pendidikan dengan Bentuk Pengelolaan}

Coefficients $^{a}$

\begin{tabular}{|c|c|c|c|c|c|c|}
\hline \multirow{2}{*}{\multicolumn{2}{|c|}{ Model }} & \multicolumn{2}{|c|}{ Unstandardized Coefficients } & \multirow{2}{*}{$\begin{array}{c}\text { Standardized } \\
\text { Coefficients }\end{array}$} & \multirow[b]{2}{*}{$t$} & \multirow[b]{2}{*}{ Sig. } \\
\hline & & $\mathrm{B}$ & Std. Error & & & \\
\hline \multirow[t]{2}{*}{1} & (Constant) & 984 & 329 & & 2,994 &, 004 \\
\hline & Tingkat_pendidikan &, 582 & 101 &, 555 & 5,781 &, 000 \\
\hline
\end{tabular}

a. Dependent Variable: Bentuk_pengelolaan

Sumber: Pengolahan Data Primer, 2017

Berdasarkan Tabel $4.32 \mathrm{di}$ atas, dapat disusun persamaan regresi sebagai berikut.

$$
Y=0.984+0.582 X_{1}
$$


Berikut penjelasan dari persamaan di atas yaitu sebagai berikut, nilai konstanta sebesar 0,984 menyatakan bahwa apabila variabel Tingkat Pendidikan $\left(X_{1}\right)$ sama dengan nol, maka bentuk pengelolaan ( $\mathrm{Y}$ ) mengalami peningkatan sebesar 0,984 satuan. Nilai koefisien $\beta_{1}=0,582$ menunjukkan bahwa terdapat pengaruh positif antara variabel tingkat pendidikan terhadap bentuk pengelolaan sebesar 0,582. Hal ini berarti apabila variabel independen tingkat pendidikan naik 1 satuan dengan asumsi bahwa variabel bebas lainnya konstan, maka variabel bentuk pengelolaan akan mengalami peningkatan sebesar 0,582 satuan. analisis regresi linier sederhana mengenai tingkat pendapatan terhadap bentuk pengelolaan disajikan dalam Tabel 4.33 berikut.

Tabel 3. Tingkat Pendapatan dengan Bentuk Pengelolaan

Correlations

\begin{tabular}{|ll|r|r|}
\hline & & $\begin{array}{c}\text { Bentuk_peng } \\
\text { elolaan }\end{array}$ & $\begin{array}{c}\text { Tingkat_pend } \\
\text { apatan }\end{array}$ \\
\hline Bentuk_pengelolaan & Pearson Correlation & 1 &, $663^{\text {*x }}$ \\
& Sig. (2-tailed) & &, 000 \\
& $\mathrm{~N}$ & 77 & 77 \\
\hline Tingkat_pendapatan & Pearson Correlation &, $663^{\text {*x }}$ & 1 \\
& Sig. (2-tailed) &, 000 & 77 \\
& $\mathrm{~N}$ & 77 & \\
\hline
\end{tabular}

**. Correlation is significant at the 0.01 level (2-tailed)

Sumber : Pengolahan Data Primer, 2017.

Berdasarkan Tabel 4.33 di atas, menunjukkan bahwa Korelasi antara tingkat pendapatan dengan bentuk penglolaan sampah adalah 0,663 dengan signifikan 0,000. Hasil tersebut menunjukkan bahwa hubungan antara tingkat pendapatan dan bentuk pengelolaan sampah adalah erat atau kuat.

\section{Tabel 4. Hasil Analisis Regresi Linier Sederhana Mengenai Tingkat} Pendapatan dengan Bentuk Pengelolaan

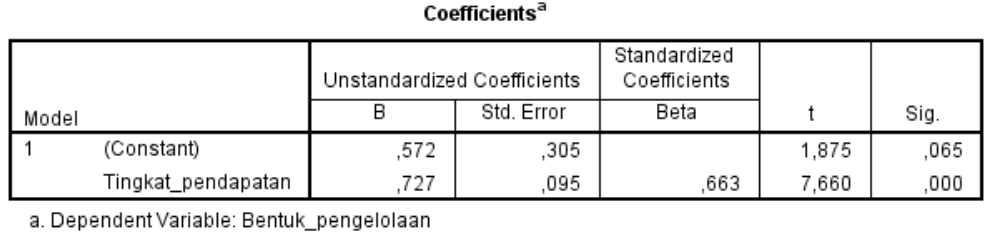

Sumber : Pengolahan Data Primer, 2017

Berdasarkan Tabel 4.34 di atas, maka dapat disusun persamaan regresi sebagai berikut:

$$
\mathrm{Y}=\mathbf{0 , 5 7 2}+\mathbf{0 , 7 2 7 \mathrm { X } _ { 2 }}
$$

Berikut penjelasan dari persamaan di atas yaitu sebagai berikut, nilai konstanta sebesar 0,572 menyatakan bahwa apabila variabel Tingkat Pendapatan $\left(\mathrm{X}_{2}\right)$ sama dengan nol, maka bentuk 
pengelolaan (Y) mengalami peningkatan sebesar 0,572 satuan. Nilai koefisien $\beta_{2}=0,727$ menunjukkan bahwa terdapat pengaruh positif antara variabel tingkat pendapatan terhadap bentuk pengelolaan sebesar 0,727 . Hal ini berarti apabila variabel independen tingkat pendapatan naik 1 satuan dengan asumsi bahwa variabel bebas lainnya konstan, maka variabel bentuk pengelolaan akan mengalami peningkatan sebesar 0,727 satuan.

\section{Analisis Resgresi Linier Berganda} Analisis regresi linier berganda (multiple regression

Tabel 5. Hasil Analisis Regresi Linier Berganda Mengenai Tingkat Pendidikan dan Tingkat Pendapatan dengan Bentuk Pengelolaan

Coefficients $^{a}$

\begin{tabular}{|c|c|c|c|c|c|c|}
\hline \multirow[b]{2}{*}{ Mod } & & \multicolumn{2}{|c|}{ Unstandardized Coefficients } & \multirow{2}{*}{$\begin{array}{c}\begin{array}{c}\text { Standardized } \\
\text { Coefficients }\end{array} \\
\text { Beta } \\
\end{array}$} & \multirow[b]{2}{*}{$\mathrm{t}$} & \multirow[b]{2}{*}{ Sig. } \\
\hline & & $\mathrm{B}$ & Std. Error & & & \\
\hline \multirow[t]{3}{*}{1} & (Constant) & .073 & .321 & & .227 & 821 \\
\hline & Tingkat_pendidikan & ,328 &, 096 &, 313 & 3,410 & ,001 \\
\hline & Tingkat_pendapatan & .565 & 101 & .515 & 5,619 & .000 \\
\hline
\end{tabular}

Sumber: Pengolahan Data Primer, 2017 analysis) merupakan model yang digunakan untuk menganalisis pengaruh lebih dari satu variabel dependen. Analisis linier berganda ini digunakan untuk mengetahui besarnya pengaruh tingkat pendidikan dan tingkat pendapatan terhadap bentuk pengelolaan sampah anorganik rumah tangga di Desa Alasangker. Hasil perhitungan analisis linier berganda yang dijabarkan dengan menggunakan program SPSS versi 22. Hasil analisis regresi linier berganda disajikan pada tabel 4.35 berikut. independen terhadap satu variabel
Berdasrkan Tabel 4.35 di atas, dapat disusun persamaan regresi sebagai berikut:

$$
Y=0,073+0,328 X_{1}
$$
.

Hasil persamaan regresi linier berganda di atas menunjukkan besar dan arah pengaruh masing- masing variabel bebas pada variabel terikatnya. Koefisien regresi yang memiliki nilai positif berarti memiliki pengaruh yang searah.

Tabel 6. Hasil Uji t Statistik

Coefficients $^{\mathrm{a}}$

\begin{tabular}{|c|c|c|c|c|c|c|}
\hline \multirow[b]{2}{*}{ Mod } & & \multicolumn{2}{|c|}{ Unstandardized Coefficients } & $\begin{array}{c}\text { Standardized } \\
\text { Coefficients }\end{array}$ & \multirow[b]{2}{*}{$t$} & \multirow[b]{2}{*}{ Sig. } \\
\hline & & B & Std. Error & Beta & & \\
\hline \multirow[t]{3}{*}{1} & (Constant) &, 073 &, 321 & &, 227 & 821 \\
\hline & Tingkat_pendidikan & ,328 &, 096 &, 313 & 3,410 & ,001 \\
\hline & Tingkat_pendapatan &, 565 & 101 & 515 & 5,619 &, 000 \\
\hline
\end{tabular}

a. Dependent Variable: Bentuk_pengelolaan

Sumber: Pengolahan Data Primer, 2017

Adapun kesimpulan yang didapatkan dari analisis tersebut antara lain sebagai berikut.

$\mathbf{H}_{1}$ : Variabel Tingkat Pendidikan mempunyai pengaruh yang positif dan signifikan terhadap bentuk pengelolaan diterima pada tingkat signifikansi 0,05 atau $5 \%$. Atau dengan kata lain: Peneliti yakin 50,2\% 
bahwa: Tingkat pendidikan mempunyai pengaruh yang signifikan terhadap bentuk pengelolaan.

$\mathbf{H}_{2}$ : Variabel Tingkat Pendapatan mempunyai pengaruh yang positif dan signifikan terhadap Uji F Statistik

bentuk pengelolaan diterima pada tingkat signifikansi 0,05 atau 5\%. Atau dengan kata lain: Peneliti yakin 50,2\% bahwa: Tingkat pendapatan mempunyai pengaruh yang signifikan terhadap bentuk pengelolaan.

Tabel 7. Hasil Uji F Statistik

ANOVA

\begin{tabular}{|ll|r|r|r|r|c|}
\hline \multicolumn{1}{|c|}{} & \multicolumn{1}{c|}{$\begin{array}{c}\text { Sum of } \\
\text { Model }\end{array}$} & Squares & df & Mean Square & \multicolumn{1}{c|}{ F } & Sig. \\
\hline 1 & Regression & 79,183 & 2 & 39,592 & 39,310 &, $000^{\mathrm{b}}$ \\
& Residual & 74,531 & 74 & 1,007 & & \\
& Total & 153,714 & 76 & & & \\
\hline
\end{tabular}

a. Dependent Variable: Bentuk_pengelolaan

b. Predictors: (Constant), Tingkat_pendapatan, Tingkat_pendidikan

Sumber: Pengolahan Data Primer, 2017

Membandingkan nilai $F_{\text {hitung }}$ dengan $F_{\text {tabel }}$ yakni $39,310>3,12$ dan nilai sig. $F$ lebih kecil dari nilai probabilitas yakni $0,000<0,05$, maka $\mathrm{H}_{0}$ ditolak atau $\mathrm{H}_{\mathrm{a}}$ diterima. Ini menunjukkan bahwa variabel tingkat pendidikan dan tingkat pendapatan secara bersama-sama berpengaruh signifikan terhadap bentuk pengelolaan. Variabel tingkat pendidikan dan tingkat pendapatan secara bersama-sama berpengaruh signifikan terhadap bentuk pengelolaan dapat diterima pada tingkat signifikansi 0,05 atau $5 \%$.

\section{Pengaruh Tingkat Pendidikan Terhadap Bentuk Pengelolaan Sampah Anorganik Rumah Tangga Di Desa Alasangker.}

Tabel 8. Hasil Tingkat Pendidikan Dan Bentuk Pengelolaan Sampah Anorganik Yang Digunakan Oleh Masyarakat Desa Alasangker

\begin{tabular}{|c|c|c|c|c|c|c|c|c|c|c|c|c|c|c|c|}
\hline \multirow{3}{*}{$\begin{array}{l}\mathrm{N} \\
\mathrm{O}\end{array}$} & \multirow{3}{*}{$\begin{array}{c}\text { Tingkat } \\
\text { Pendidikan }\end{array}$} & \multicolumn{14}{|c|}{ Bentuk Pengelolaan } \\
\hline & & \multicolumn{2}{|c|}{ Reduce } & \multicolumn{2}{|c|}{ Reuse } & \multicolumn{2}{|c|}{ Recycle } & \multicolumn{2}{|c|}{$\begin{array}{l}\text { Langsung } \\
\text { dibuang }\end{array}$} & \multicolumn{2}{|c|}{$\begin{array}{l}\text { Men } \\
\text { Jual }\end{array}$} & \multicolumn{2}{|c|}{$\begin{array}{c}\text { Memb } \\
\text { akar }\end{array}$} & \multicolumn{2}{|c|}{ Total } \\
\hline & & $\mathbf{N}$ & $\%$ & $\mathbf{N}$ & $\%$ & $\mathbf{N}$ & $\%$ & $\mathbf{N}$ & $\%$ & $\mathbf{N}$ & $\%$ & $\mathbf{N}$ & $\%$ & $\mathbf{N}$ & $\%$ \\
\hline 1 & $\begin{array}{c}\text { Tidak sekolah } \\
\text { dan tidak tamat } \\
\text { SD }\end{array}$ & 0 & 0,0 & 0 & 0,0 & 0 & 0,0 & 2 & 11,1 & 6 & 46,2 & 4 & 44,4 & 12 & 15,6 \\
\hline 2 & SD & 1 & 14,3 & 5 & 19,2 & 1 & 25,0 & 10 & 55,6 & 5 & 38,5 & 0 & 0,0 & 22 & 28,6 \\
\hline 3 & SLTP & 1 & 14,3 & 4 & 15,4 & 2 & 50,0 & 3 & 16,7 & 0 & 0,0 & 2 & 22,2 & 12 & 15,6 \\
\hline 4 & SLTA & 1 & 14,3 & 10 & 38,5 & 1 & 25,0 & 3 & 16,7 & 2 & 15,4 & 1 & 11,1 & 18 & 23,4 \\
\hline 5 & $\begin{array}{c}\text { Perguruan } \\
\text { Tinggi }\end{array}$ & 4 & 57,1 & 7 & 26,9 & 0 & 0,0 & 0 & 0,0 & 0 & 0,0 & 2 & 22,2 & 13 & 16,9 \\
\hline & Total & 7 & 100 & 26 & 100 & 4 & 100 & 18 & 100 & 13 & 100 & 9 & 100 & 77 & 100 \\
\hline
\end{tabular}

Sumber : Pengolahan Data Primer, 2017.

Hasil analisis data dalam penelitian menunjukkan bahwa tingkat pendidikan berpengaruh positif dan signifikan terhadap bentuk pengelolaan sampah anorganik rumah tangga di Desa Alasangker. Pengelolaan sampah yang baik merupakan hal penting bagi siapapun guna menjamin kualitas kesehatan. Sampah yang paling sulit terurai dalam tanah adalah sampah anorganik. Penanganan sampah anorganik dapat dilakukan dengan 
tiga cara, yaitu reduce, reuse dan recycle (daur ulang) (Marliani,2014).

Tingkat pendidikan yang paling tinggi yaitu perguruan tinggi dominan untuk menggunakan bentuk pengelolaan Reuse (menggunakan kembali) sampah anorganik dan tingkat pendidikan yang rendah yaitu Tidak Sekolah dan Tidak Tamat SD dominan untuk menggunakan bentuk pengelolaan menjual dan membakar sampah anorganik. Hasil penelitian ini sesuai dengan temuan Mifbakhuddin (2010) hasil penelitiannya menyatakan bahwa setelah dilakukan uji korelasi spearman pada variabel pendidikan yang di nyatakan pada diagram tabel terlihat pola positif yang artinya semakin tinggi pendidikan responden maka semakin baik pengelolaan sampahnya.

Penelitian Riswan, dkk (2011) juga mengemukakan hasil penelitiannya bahwa tingkat pendidikan berkorelasi positif dengan pengelolaan sampah rumah tangga. Penelitian Purnama Putra, dkk (2013) juga mengemukakan hasil penelitiannya bahwa ada hubungan positif antara tingkat tingkat pendidikan dengan sikap kepala keluarga terhadap pengelolaan sampah rumah tangga dan yang terakhir dari penelitian Hayana (2015) menyatakan bahwa meningkatnya pendidikan ibu rumah tangga tentang lingkungan maka partisipasi dalam usaha pengelolaan sampah cenderung akan semakin meningkat.

\section{Pengaruh Tingkat Pendapatan Terhadap Bentuk Pengelolaan Sampah Anorganik Rumah Tangga Di Desa Alasangker.}

Tabel 9. Hasil Tingkat Pendapatan Dan Bentuk Pengelolaan Sampah Anorganik Yang Digunakan Oleh Masyarakat Desa Alasangker

\begin{tabular}{|c|c|c|c|c|c|c|c|c|c|c|c|c|c|c|c|}
\hline \multirow[t]{3}{*}{ No } & \multirow{3}{*}{$\begin{array}{c}\text { Tingkat } \\
\text { Pendapatan } \\
\text { (Rp) }\end{array}$} & \multicolumn{14}{|c|}{ Bentuk Pengelolaan } \\
\hline & & \multicolumn{2}{|c|}{ Reduce } & \multicolumn{2}{|c|}{ Reuse } & \multicolumn{2}{|c|}{ Recycle } & \multicolumn{2}{|c|}{$\begin{array}{c}\text { Lang } \\
\text { sung } \\
\text { dibuang }\end{array}$} & \multicolumn{2}{|c|}{$\begin{array}{c}\text { Men } \\
\text { jual }\end{array}$} & \multicolumn{2}{|c|}{$\begin{array}{c}\text { Memba } \\
\text { kar }\end{array}$} & \multicolumn{2}{|c|}{ Total } \\
\hline & & $\mathbf{N}$ & $\%$ & $\mathbf{N}$ & $\%$ & $\mathbf{N}$ & $\%$ & $\mathbf{N}$ & $\%$ & $\mathbf{N}$ & $\%$ & $\mathbf{N}$ & $\%$ & $\mathbf{N}$ & $\%$ \\
\hline 1 & $<500.000$ & 0 & 0,0 & 1 & 3,8 & 0 & 0,0 & 1 & 5.6 & 7 & 53,8 & 3 & 33,3 & 12 & 15,6 \\
\hline 2 & $\begin{array}{l}500.000- \\
1.000 .000 \\
\end{array}$ & 1 & 14,3 & 1 & 3,8 & 0 & 0,0 & 7 & 38,9 & 5 & 38,5 & 4 & 44,4 & 18 & 23,4 \\
\hline 3 & $\begin{array}{l}>1.000 .000 \\
-1.500 .000\end{array}$ & 1 & 14,3 & 8 & 30,8 & 3 & 75,0 & 7 & 38,9 & 1 & 7,7 & 1 & 11,1 & 21 & 27,3 \\
\hline 4 & $\begin{array}{l}>1.500 .000 \\
-2.000 .000\end{array}$ & 0 & 0,0 & 12 & 46,2 & 0 & 0,0 & 2 & 11,1 & 0 & 0,0 & 0 & 0,0 & 14 & 18,2 \\
\hline 5 & $>2.000 .000$ & 5 & 71,4 & 4 & 15,4 & 1 & 25,0 & 1 & 5,6 & 0 & 0,0 & 1 & 11,1 & 12 & 15,6 \\
\hline & Total & 7 & 100 & 26 & 100 & 4 & 100 & 18 & 100 & 13 & 100 & 9 & 100 & 77 & 100 \\
\hline
\end{tabular}

Sumber : Pengolahan Data Primer, 2017.

Hasil analisis data dalam penelitian menunjukkan bahwa tingkat pendapatan berpengaruh positif dan signifikan terhadap bentuk pengelolaan sampah anorganik rumah tangga di Desa Alasangker. Pengelolaan sampah yang baik merupakan hal penting bagi siapapun guna menjamin kualitas kesehatan. Sampah yang paling sulit terurai dalam tanah adalah sampah anorganik. Penanganan sampah anorganik dapat dilakukan dengan tiga cara, yaitu reduce, reuse dan recycle (daur ulang) (Marliani,2014). 
Tingkat Pendapatan yang tinggi yaitu lebih dari Rp. 2000.000 lebih dominan untuk menggunakan bentuk pengelolaan Reduce (mengurangi sampah anorganik dan tingkat pendapatan yang paling rendah yaitu kurang dari Rp. 500.000 lebih dominan untuk menggunakan bentuk pengelolaan menjual sampah anorganik. Hasil penelitian ini sesuai dengan temuan Mifbakhuddin, dkk (2010) hasil penelitiannya menyatakan bahwa setelah dilakukan uji korelasi spearman pada variabel pendapatan yang di nyatakan pada diagram tabel terlihat pola positif yang artinya semakin tinggi pendapatan responden maka semakin baik pengelolaan sampahnya.

Riswan, dkk (2011) juga menunjukkan hasil yang sama bahwa hasil uji korelasi spearman menyatakan bahwa tingkat pendapatan keluarga berkorelasi positif dengan cara pengelolaan sampah rumah tangga. Penelitian Purnama Putra (2013) juga menyatakan bahwa seseorang yang memiliki pendapatan tinggi menunjukkan partisipasi sikap yang tinggi dalam mengelola sampah rumah tangga, dan penelitian yang terakhir yaitu Hayana (2015) menyatakan bahwa responden yang memiliki pendapatan rendah maka tingkat partisipasinya rendah, sementara responden yang memiliki penghasilan tinggi maka tingkat partisipasinya tinggi pula.

\section{Pengaruh Tingkat Pendidikan dan Tingkat Pendapatan Terhadap Bentuk Pengelolaan Sampah Anorganik Rumah Tangga Di Desa Alasangker.}

Hasil analisis data dalam penelitian menunjukkan bahwa tingkat pendidikan dan tingkat pendapatan berpengaruh positif dan signifikan terhadap bentuk pengelolaan sampah anorganik rumah tangga di Desa Alasangker.

Tingkat pendidikan dan tingkat pendapatan bersama-sama berpengaruh terhadap bentuk pengelolaan sampah anorganik rumah tangga di Desa Alasangker namun, yang paling berpengaruh terhadap bentuk pengelolaan sampah anorganik adalah tingkat pendapatan yang memiliki nilai koefisien 0,565 sehingga dapat disimpulkan bahwa tingkat pendapatan lebih berpengaruh terhadap bentuk pengelolaan sampah anorganik rumah tangga di Desa Alasangker.

Hasil penelitian ini sesuai dengan temuan Mifbakhuddin, dkk (2010) hasil penelitiannya menyatakan bahwa tingkat pendidikan dan tingkat pendapatan secara bersama-sama setelah dilakukan uji korelasi sperman pada variabel dinyatakan pada diagram tabel terlihat pola positif terhadap pengelolaan sampahnya. Riswan, dkk (2011) pada hasil penelitiannya juga menyatakan bahwa tingkat pendidikan dan tingkat pendapatan keluarga berkorelasi positif dengan cara pengelolaan sampah rumah tangga. Penelitian Purnama Putra (2013) pada hasil penelitiannya juga menyatakan bahwa seseorang yang memiliki tingkat pendidikan dan tingkat pendapatan tinggi menunjukkan partisipasi sikap yang tinggi dalam mengelolan sampah rumah tangga, masyarakat yang memiliki tingkat pendidikan dan tingkat pendapatan rendah cenderung enggan untuk mengelola sampah rumah tangganya, selanjutnya penelitian yang terakhir yaitu penelitian Hayana (2015) hasil penelitiannya juga menyatakan variabel tingkat pendidikan dan tingkat pendapatan berpengaruh positif terhadap partisipasi pengelolaan sampah. 


\section{SIMPULAN DAN SARAN}

Tingkat pendidikan berpengaruh positif dan signifikan terhadap bentuk pengelolaan sampah anorganik rumah tangga di Desa Alasangker. Adanya peningkatan variabel tingkat pendidikan akan mempertinggi bentuk pengelolaan sampahnya. Berdasarkan hasil pengujian hipotetis pertama, variabel tingkat pendidikan mempunyai pengaruh positif dan signifikan terhadap bentuk pengelolaan sampah anorganik. Hal ini dibuktikan dengan nilai signifikansi sebesar $0,001<0,05$, dan nilai $t$ sebesar 0,328 . Jadi dapat disimpulkan bahwa hipotetis pertama diterima dan hasil penelitian sesuai dengan teori yang sudah ada. Bentuk pengelolaan berdasarkan tingkat pendidikan yang paling tinggi yaitu perguruan tinggi menggunakan bentuk pengelolaan reuse (menggunakan kembali) dan tingkat pendidikan yang paling rendah yaitu tidak sekolah atu tidak tamat SD dominan untuk penggunakan bentuk pengelolaan dengan cara membakar.

Tingkat pendapatan berpengaruh positif dan signifikan terhadap bentuk pengelolaan sampah anorganik rumah tangga di Desa Alasangker. Adanya peningkatan variabel tingkat pendapatan akan mempertinggi bentuk pengelolaan sampahnya. Berdasarkan hasil pengujian hipotetis kedua, variabel tingkat pendapatan mempunyai pengaruh positif dan signifikan terhadap bentuk pengelolaan sampah anorganik. Hal ini dibuktikan dengan nilai signifikansi sebesar $0,000<$ 0,05 , dan nilai t sebesar 0,565 . Jadi dapat disimpulkan bahwa hipotetis kedua diterima dan hasil penelitian sesuai dengan teori yang sudah ada. Bentuk pengelolaan berdasarkan tingkat pendapatan yang paling tinggi yaitu lebih dari Rp. 2.000.000 lebih dominan untuk menggunakan bentuk pengelolaan reuse (mengurangi) dan tingkat pendapatan yang paling rendah yaitu kurang dari Rp.500.000 lebih dominan untuk menjual sampah anorganik.

Tingkat pendidikan dan tingkat pendapatan secara bersama-sama berpengaruh positif dan signifikan terhadap bentuk pengelolaan sampah anorganik rumah tangga di Desa Alasangker. Dengan nilai probabilitas sebesar $0,000<0,05$, dan nilai $F$ 39,310. Bentuk pengelolaan berdasarkan tingkat pendidikan yang paling tinggi yaitu perguruan tinggi menggunakan bentuk pengelolaan reuse (menggunakan kembali) dan tingkat pendidikan yang paling rendah yaitu tidak sekolah atu tidak tamat SD dominan untuk penggunakan bentuk pengelolaan dengan cara membakar. Bentuk pengelolaan berdasarkan tingkat pendapatan yang paling tinggi yaitu lebih dari Rp. 2.000.000 lebih dominan untuk menggunakan bentuk pengelolaan reuse (mengurangi) dan tingkat pendapatan yang paling rendah yaitu kurang dari Rp.500.000lebih dominan untuk menjual sampah anorganik. Yang paling berpengaruh terhadap pengelolaan sampah anorganik yaitu tingkat pendapatan dengan nilai koefisien 0,565.

$$
\text { Bagi masyarakat Desa }
$$

Alasangker, diperlukan peningkatan bentuk pengelolaan sampah anorganik karena suatu upaya untuk mengurangi dampak negatif dari sampah anorganik. Peningkatan bentuk pengelolaan sampah anorganik dilakukan dengan aktif mengikuti program pemerintah 
terkait bentuk pengelolaan sampah anorganik.

Bagi pemerintah Desa

Alasangker, agar meningkatkan sosialisasi/ penyuluhan terkait bentuk pengelolaan sampah anorganik guna meningkatkan pengetahuan masyarakat. Sampah

\section{Daftar Pustaka}

Beni, Martinus Tulit, IGB Arjana, dan Ruslan Ramang. 2014. "Pengaruh Faktor-Faktor Sosial Ekonomi Terhadap Perilaku Pengelolaan Sampah Domestik di Nusa Tenggara Timur". Jurnal IImu Lingkungan, Vol. 12, Nomor 2, (Halaman 106-114).

Cristiawan, Putu Indra dan Citra, I Putu Ananda. 2016. "Studi Timbulan Dan Komposisi Sampah Perkotaan Di Kelurahan Banyuning". Jurnal Media Komunikasi Geografi, Vol. 17, Nomor 2, (Halaman 5 - 23)

Fitriana, Ayu dan Soedirham. 2013. "Prilaku Ibu Rumah Tangga Dalam Pengelolaan Sampah di Desa Bluru Kidul RW II Kecamatan Sidoarjo". Jurnal Promkes, Vol. 1, Nomor 2, (Halaman 101-136).

Hayana. 2015. "Hubungan Sosial Ekonomi dan Budaya terhadap Partisipasi Ibu Rumah Tangga dalam Pengelolaan Sampah di Kecamatan Bangkinang". Jurnal Kesehatan Komunitas, Vol. 2, Nomor 6, (Halaman 17).

Himawanto, Dwi Aries. 2007. "Karakteristik Panel Akustik Sampah Kota Pada Frekuensi Rendah anorganik selain memiliki dampak positif bagi masyarakat juga memiliki dampak negatif bagi lingkungan dan manusia, sehingga guna mengurangi dampak negatif maka perlu adanya sosialisasi tentang bentuk pengelolaan sampah anorganik rumah tangga.

$$
\begin{aligned}
& \text { dan Frekuensi Tinggi } \\
& \text { Akibat Variasi Kadar } \\
& \text { Bahan Anorganik". } \\
& \text { Jurnal Teknik Gelagar, } \\
& \text { Vol. 18, Nomor 01, } \\
& \text { (Halaman 3-22). }
\end{aligned}
$$

Marleni, Yeti, Rohiddin Marsyah, dan Bieng Brata. 2012. "Strategi Pengelolaan Sampah Rumah Tangga di Kelurahan Kota Medan Kecamatan Kota Manna Kabupaten Bengkulu Selatan". Jurnal Penelitian Pengelolaan

Sumberdaya Alam dan Lingkungan, Vol. 1, Nomor 1, (Halaman 2-7).

Marliani, Novi. 2014. "Pemanfaatan Limbah Rumah Tangga (Sampah Anorganik) Sebagai Bentuk Implementasi Dari Pendidikan Lingkungan Hidup". Jurnal Formatif, Vol 4, Nomor 2, (Halaman 6-12).

Mifbakhuddin, Trixie Salawati, dan Arif Kasmudi. 2010. "Gambaran Pengelolaan Sampah Rumah Tangga Tinjauan Aspek Pendidikan,

Pengetahuan, dan Pendapatan Perkapita di RT 6 RW 1 Kelurahan Pedurungan Tengah Semarang". Jurnal Kesehatan Masyarakat 
Indonesia, Vol. 6, Nomor 1, (Halaman 3-14).

Migristine, Rinrin. 2014. Pengolahan Sampah Plastik.

Bandung: Titian IImu Bandung.

Putra, Hijrah Purnama. 2013."Studi Hubungan antara Tingkat pendidikan dan Pendapatan Keluarga terhadap Sikap dalam Pengelolaan Sampah Rumah Tangga (study kasus di Desa Condongcatur, Depok, sleman, Yogyakarta)". Jurnal Sains dan Teknologi Lingkungan, Vol. 5, Nomor 2, (Halaman 81-100).

Riswan, dkk. 2011. "Pengelolaan Sampah Rumah Tangga di Kecamatan Daha Selatan". Jurnal IImu
Lingkungan, Vol. 9, Nomor 1, (Halaman 1-9).

Sucipto, Cecep Dani. 2012. Teknologi Pengolahan Daur Ulang Sampah. Yogyakarta: Gosyen Publishing.

Suprapto. 2010. 'Hubungan Antara Jenjang Pendidikan Dan Pendapatan Dengan Sikap Kepala Keluarga Terhadap Pengelolaan Sampah Rumah Tangga Di Desa Candisari Kabupaten Grobongan Tahun 2010". Tesis. Program Pasca Sarjana. Universitas Sebelas Maret. Surakarta. (Halaman 93- 116)

Undang-Undang Republik Indonesia Nomor 18 Tahun 2008 tentang Pengelolaan Sampah. 